\title{
Original Research \\ Impact of Patient Portal Use on Duplicate Laboratory Tests \\ in Diabetes Management
}

Bonnie J. Wakefield, PhD, ${ }^{1,2}$ Carolyn Turvey, $P h D_{1}^{1,3,4}$ Timothy Hogan, PhD, ${ }^{5,6}$ Stephanie Shimada, $P h D_{1}^{5,6}$ Kim Nazi, PhD, ${ }^{7}$ Lishan Cao, MS, ${ }^{8}$ Kevin Stroupe, $P h D_{1}^{8,9}$ Rachael Martinez, $P h D^{8}$ and Bridget Smith, $P h D^{8,10}$

${ }^{1}$ Center for Access and Delivery Research and Evaluation, lowa City Veterans Affairs Healthcare System, Iowa City, Iowa, USA.

${ }^{2}$ Sinclair School of Nursing, University of Missouri, Columbia, Missouri, USA.

${ }^{3}$ Rural Health Resource Center, lowa City Veterans Affairs Healthcare System, lowa City, Iowa, USA.

${ }^{4}$ Department of Psychiatry College of Medicine, University of lowa, lowa City, lowa, USA.

${ }^{5}$ Center for Healthcare Organization and Implementation Research, Edith Nourse Rogers Memorial Veterans Hospital, Bedford, Massachusetts, USA.

${ }^{6}$ Division of Health Informatics and Implementation Science, Population and Quantitative Health Sciences, University of Massachusetts Medical School, Worcester, Massachusetts, USA.

${ }^{7}$ Independent Consultant, Albany, New York, USA.

${ }^{8}$ Center of Innovation for Complex Chronic Healthcare, Hines VA Hospital, Hines, Illinois, USA.

${ }^{9}$ Stritch School of Medicine, Loyola University Chicago, Maywood, Illinois, USA.

${ }^{10}$ Center for Healthcare Studies, Institute of Public Health and Medicine, Northwestern University Feinberg School of Medicine, Chicago, Illinois, USA.

\section{Abstract}

Background: Patients seek care across multiple health care settings. One coordination issue is the unnecessary duplication of laboratory across different health care settings. This analysis examined the association between patient portal use and duplication of laboratory testing among Veterans who are dual users of Veterans Affairs (VA) and non-VA providers.

Materials and Methods: A national sample of Veterans who were newly authenticated users of the portal during fiscal year (FY) 2013 who used Blue Button at least once were compared with a random sample of Veterans who were not registered to use the portal. From these two groups, Veterans who were also Medicare-eligible users in FY2014 were identified. Duplicate testing was defined as receipt of more than five $\mathrm{HbA1c}$ (hemoglobin A1c) in 1 year.
Results: Use of the Blue Button decreased the odds of duplicate HbA1c testing in VA and Medicare-covered facilities across three comparisons: (1) overall between users and nonusers: portal users were less likely to have duplicate testing; (2) prepost comparison: there was a trend toward lower duplicate testing in both groups across time; and (3) pre-post comparisons accounting for use of the portal: the trend toward lower duplicate testing was greater in Blue Button users.

Conclusion: Duplicate HbA1c testing was significantly lower in dual users of VA and Medicare services who used the Blue Button feature of their VA patient portal. Non-VA providers encounter barriers to access of complete information about Veterans who also use VA health care. Provider endorsement of consumer-mediated health information exchange could help further this model of sharing information.

Keywords: telemedicine, patient portals, health information exchange, electronic health records, Veterans, diabetes

\section{Introduction}

A s modern health care continues to become more fragmented and patients seek care across multiple settings, there is increased potential for coordination issues. One pressing coordination issue is the potential for waste, including the unnecessary duplication of laboratory or imaging test ordering by providers working in different health care settings. While duplication of these services may be driven by provider preferences, patient requests, and other factors, ${ }^{1}$ repeated laboratories and images are often due to lack of sharing of patient information across providers and systems of care. ${ }^{2}$ Duplication of laboratory testing has been estimated at 32\%, with $20 \%$ of duplicated tests not clinically indicated, meaning that the test would not have been ordered if prior results were known to the provider. ${ }^{3}$ While there are limited studies on duplicate testing in Veterans Affairs (VA) facilities, Maciejewski et al. ${ }^{4}$ examined overtesting and undertesting among Veterans who used only VA services and those who were "dual users" (i.e., Veterans who are eligible for and receive care through VA and in non-VA care settings). Overtesting was defined as five or more HbA1c tests per year. 
They found that compared with VA-only users, dual users were twice as likely to have too many glycohemoglobin (i.e., hemoglobin A1c or HbA1c) tests, which reflect a patient's average blood sugar level over the previous 3 months and are used to diagnose and monitor type 1 and type 2 diabetes, and too many albumin tests, which are used to diagnose and monitor liver and kidney conditions. Across health care systems, the potential for duplication of services is highest and most problematic among patients with chronic diseases such as diabetes. ${ }^{5}$ Prevalence rates of diabetes continue to rise and the selfmanagement tasks associated with the condition are ongoing, often requiring patients to undergo a variety of tests, laboratories, and consultations with different providers to address related issues.

Use of electronic health records (EHRs) is purported to facilitate electronic health information exchange (HIE) across providers and systems of care. However, the evidence is mixed as to whether EHRs and HIE systems reduce duplicate diagnostic and laboratory testing, and thus costs of care. In a recent systematic review of 25 studies that evaluated the effect of HIE on quality and/or costs, slightly over half (60\%) found HIE cost-effective. ${ }^{6}$ Conversely, some studies found higher costs associated with HIE adoption. ${ }^{7,8}$ Any patient may at times choose to seek care beyond his or her usual provider or health care system, thus increasing the risk of duplication of services. However, dual use is an ongoing coordination issue for VA facilities, where Veterans who are $\geq 65$ years of age are eligible for VA services and may also use Medicare to access care and cover health expenses. Recent studies have also shown that dual use is common among working-age Veterans (those under age 65) to address both inpatient and outpatient care needs, ${ }^{9-11}$ particularly in rural areas. One study found that 54\% of rural dwelling Veterans used both VA and private insurances. ${ }^{9}$ Furthermore, higher risk Veteran patients (i.e., those with higher Hierarchical Condition Category [HCC] scores) are more likely to be dual users. ${ }^{10}$

\section{CONSUMER-MEDIATED HIE AND THE ROLE OF PATIENT PORTAL FEATURES}

Although dual use can increase access to care for some patients, it also increases the likelihood of care discontinuity across settings. ${ }^{12}$ Consumer-mediated HIE, a term that refers to patients aggregating and controlling their own health information, ${ }^{13}$ is becoming increasingly available and may help alleviate problems associated with lack of communication across systems and providers. Blue Button, one feature of consumer-mediated HIE, enables patients to have more direct access to view, download, and transmit their health information in formats that are machine and human readable. ${ }^{14,15}$
An initiative launched by VA in 2010 to promote the adoption and use of Blue Button functionality has since expanded to other federal agencies and private sector organizations committed to advancing consumer-mediated HIE. ${ }^{16}$ Although wide variation exists in the frequency with which patients access and use portal features, ${ }^{17}$ online laboratory test results are among the most commonly used portal features. ${ }^{18}$

\section{VA PATIENT PORTAL}

In VA, the patient portal is called My HealtheVet (MHV). MHV employs a tiered access model, with varied access to information and features depending on a Veteran's portal account type. Full access to portal features is available to those who complete a one-time, identity authentication process either in-person or online. Importantly, users with these premium accounts have access to key portions of their VA medical record, including laboratory results, through the VA Blue Button. The VA Blue Button enables Veterans to access and download a copy of their VA health records into a text, PDF, or XML file that can be read, printed, or saved on a computer. Veterans may select the date range and type of information to include for text and PDF files. They may also generate a VA Health Summary; a single standardized interoperable electronic file called the Continuity of Care Document (CCD) ${ }^{19-21}$ that includes a comprehensive summary of their VA health information focusing on the prior 24 months of treatment.

The number of Veterans who use MHV continues to increase, with $>2.9$ million having identity-authenticated, premium accounts as of February 2019. ${ }^{22}$ The effect of the MHV portal on care coordination issues has received scant attention, with the exception of some preliminary studies, suggesting that engaging patients in portal use to access laboratory information may empower them to improve information sharing between disparate providers and health care systems. ${ }^{21,23}$ Specific to the context of diabetes, although some studies have found improved glycemic control in patient portal users, ${ }^{24-26}$ there is limited evidence that use of portal features actually impacts duplicative tests. To our knowledge, there are no studies examining the effect of portal use on duplication of services among dual users of VA and Medicare services despite the many Veterans who seek care in both VA and Medicare feefor-service settings. As such, the purpose of this analysis was to examine the association between MHV portal use and duplication of laboratory testing among patients who are dual users of VA and Medicare services. We hypothesized that patient use of the Blue Button feature of the MHV portal to download and share health information is associated with decreased duplication of $\mathrm{HbA1c}$ tests in this population. 


\section{PATIENT PORTAL USE AND DUPLICATE LABORATORY TESTS}

\section{Materials and Methods}

\section{STUDY DESIGN AND SAMPLE}

Data for this analysis were drawn from a larger study ${ }^{27}$ examining MHV use among Veterans receiving health care from VA facilities, including impacts on VA health care use and dual use of services from VA and non-VA providers covered by Medicare. We chose to focus on the impact of MHV use on duplication of $\mathrm{HbA} 1 \mathrm{c}$ tests from VA and non-VA providers among VA users with diabetes based on input from VA primary care providers. Although $\mathrm{HbA1c}$ is relatively inexpensive, it is a frequently used laboratory test, and there are longstanding national guidelines for frequency of HbA1c measurement. Furthermore, overutilization of $\mathrm{HbA} 1 \mathrm{c}$ testing has been attributed to a lack of care coordination, ${ }^{28}$ which is common in VA dual users.

The study included a national sample of Veterans who were newly authenticated users of MHV during fiscal year (FY) 2013 (i.e., October 1, 2012 to September 30, 2013; pregroup) and who used Blue Button at least once to obtain laboratory data. We compared these Blue Button users with a random sample of Veterans who were not registered to use MHV. From these two groups, we identified Veterans who were also Medicareeligible users in FY2014 (October 1, 2013 to September 30, 2014; 1-year post). Dual users were defined as Veterans who had two VA outpatient visits or one VA hospitalization and two Medicare encounters in the same year. Veterans who were deceased, aged $<18$ or $>104$, and those with missing data on variables included as covariates in adjusted models (distance to nearest VA; region of residence; urban residence; enrollment; income) were excluded from the sample. Among all Veterans meeting the inclusion and exclusion criteria, we took a 10\% random sample, resulting in a final analytic sample for this analysis composed of 30,186 Veterans who use VA and Medicare health care services (Fig. 1).

\section{MEASURES AND DATA SOURCES}

Duplicate tests. We defined duplication of testing as a dichotomous indicator of receipt of more than five HbA1c tests from both a VA and a non-VA provider in 1 year. Receipt of an $\mathrm{HbA1c}$ test from a non-VA provider was assessed using Medicare claims data. VA performance metrics (consistent with standards of the American Diabetes Association) ${ }^{29-31}$ during the analysis time period indicated that HbA1c should be measured in patients with diabetes at least annually, and more frequently (up to four times per year) if clinically indicated, to assess glycemic control over time.

Demographics. Information about Veteran characteristics was obtained from the VA Medical SAS Databases, ${ }^{32}$ and in-

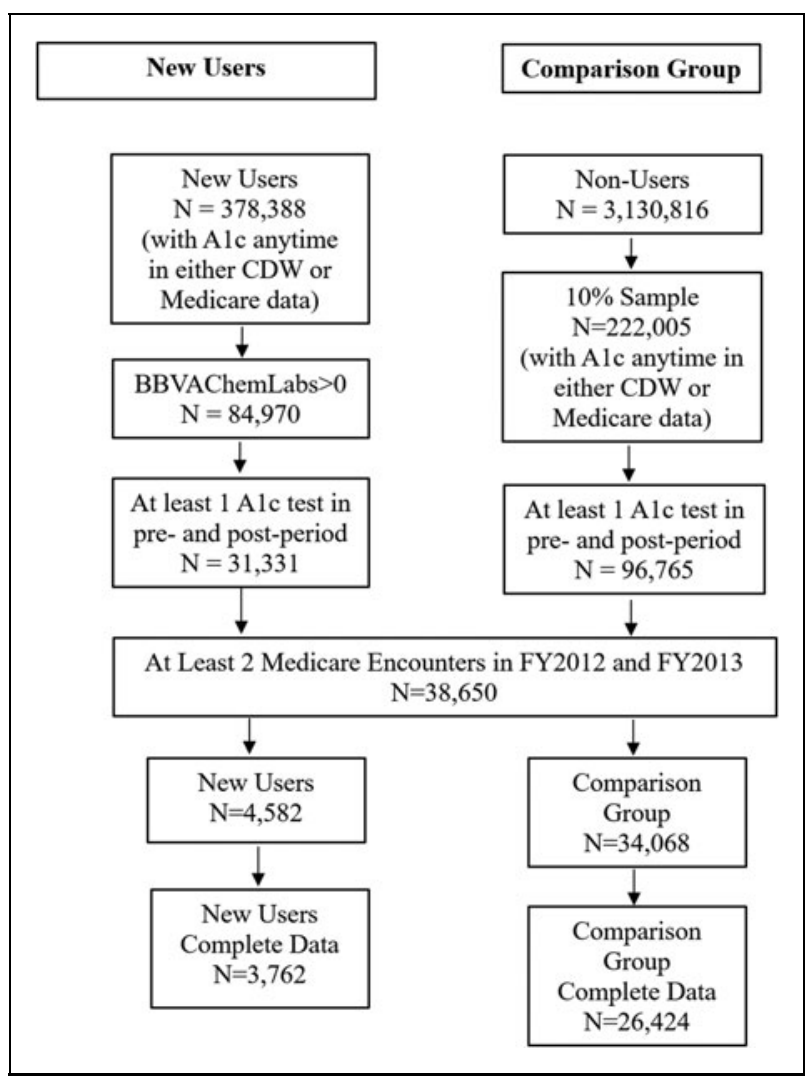

Fig. 1. Sample derivation diagram.

cluded gender, age, race, ethnicity, and U.S. geographic region of residence (i.e., Midwest, Northeast, South, West, other). The distance between the nearest VA facility to the Veteran and the ZIP code associated with the Veteran's address were used to determine Veteran distance to their nearest VA. A Veteran's VA enrollment group, a classification system used to determine copayment for VA services based on disability rating, income, and other factors (e.g., prisoner of war status), was determined using the VA Enrollment file (a file of all Veterans enrolled for care in the VHA, maintained by the VHA). Veteran's estimated income bracket was determined using census data detailing the median household income for the ZIP code associated with their residence ${ }^{33}$; this ZIP code was also used to determine the urbanicity of where the Veteran lived. ${ }^{34}$ Overall health status was estimated through the CMS HCC riskadjustment model for community-dwelling populations. ${ }^{35,36}$

$M H V$ registration and Blue Button use. Registration for MHV and use of the Blue Button laboratory feature was calculated for the Veterans in our sample within 1 year of their respective index date. Veterans were considered to have used a MHV portal feature if they had any use of that feature in this time frame (as opposed to no use). 


\section{WAKEFIELD ET AL.}

\section{ANALYSIS}

To balance characteristics between Veterans who used the MHV Blue Button laboratory feature or nonusers, we used propensity score weighting. ${ }^{37}$ We calculated the propensity score for each Veteran as the predicted probability of being a MHV Blue Button laboratory feature user, using multiple logistic regression analysis of the patient characteristics in Table 1. Each Veteran was assigned a propensity score weight based on this propensity score. To examine the impact of the propensity score weighting, we calculated weighted and unweighted standardized differences. While several of the unweighted standardized differences were $>10$, indicating a substantial difference between the Blue Button User and comparison groups, the weighted standardized differences were all $<10 .^{38}$

Because other factors may have influenced trends over time, we used difference-in-differences methodology to examine whether use of the MHV Blue Button laboratory feature was associated with receipt of duplicate $\mathrm{HbA1c}$ testing from VA and Medicare-covered facilities. Difference-in-differences estimates of duplicate receipt of $\mathrm{HbA} 1 \mathrm{c}$ testing were obtained using logistic regression analysis with propensity score weighting. The logistic regression models included indicator variables for time (pre- vs. postperiod), MHV use group, and the interaction between time and evaluation group. ${ }^{39}$

An alpha level of 0.05 was used to determine statistical significance. Statistical analyses were performed with STATA MP Version 14.2 software (Statoscope, College Station, TX). This study was approved by the Institutional Review Boards at the Edward Hines Jr. VA Hospital and Edith Nourse Rogers Memorial Veterans Hospital.

\section{Results}

Demographic and risk factor variables between MHV and non-MHV users were statistically significant $(p<0.01)(T a-$ ble 1). MHV users tended to be younger, married, white, urban dwelling, and had higher incomes and better health status (HCC score). Propensity scores standard differences were all $<0.10$, indicating balance between the two groups.

\section{DUPLICATE HвA1с TESTS}

During the baseline period (FY13), 2.34\% ( $n=88$ ) of new users and 3.09\% $(n=817)$ of nonusers had greater than five $\mathrm{HbA} 1 \mathrm{c}$ tests. The following year (FY14) $33(<1 \%)$ of new users and $699(2.65 \%)$ of nonusers had $>5 \mathrm{HbA1c}$ tests. Use of the MHV Blue Button laboratory feature was associated with a lower proportion of duplicate HbA1c testing in VA and Medicarecovered facilities across three comparisons: (1) overall between users and nonusers: MHV users were less likely to have duplicate testing; (2) pre-post comparison: there was a trend toward lower duplicate testing in both groups across time; and (3) pre-post comparisons accounting for use of MHV Blue Button: the trend toward lower duplicate testing was greater in the Blue Button users (Table 2). Other significant differences between the two groups included distance to provider, eligibility group, and risk scores (Table 2).

\section{Discussion}

Duplicate $\mathrm{HbA1c}$ testing was significantly lower in dual users of VA and Medicare services who used the Blue Button feature of their VA patient portal compared with those who did not. While the cost per HbA1c is relatively low, the frequency of use is high, thus lowering duplicative testing will likely result in cost savings. Veterans and health care providers report satisfaction and perceived value in consumermediated HIE supported by PHR portal features. ${ }^{40}$ A next step in building the evidence for this model of information exchange is further study of its impact on markers of safety and quality, including duplicate testing. Our study is among the first to consider this in a sample of Veterans who receive services through both VA and Medicare.

Prior work has demonstrated a decrease in duplication in diagnostic studies with HIE, ${ }^{41-46}$ but these studies focused on provider-provider exchange. Veteran patients who are downloading and sharing data with their non-VA providers have essentially developed a workaround (e.g., using patientmediated medical records) in which they share information between their VA and non-VA providers because it is needed due to systems structures, including the challenges of non-VA physician access to the VA EHR.

Recent studies have examined the potential for MHV to reduce duplication of services. In single arm interventional study, 90\% of providers reported that the CCD available through the VA Blue Button improved their ability to have an accurate medication list and helped them make medication treatment decisions, and 50\% reported that they did not order a laboratory test or another procedure because of information available in the CCD. ${ }^{23}$ In one small pilot randomized trial $(N=52)$, Veterans trained to share their CCD with non-VA providers had significantly fewer duplicate laboratory tests than the comparator attention control group. However, the intervention was not effective when providers ordered laboratories to be drawn in the week before the actual medical visit. $^{21}$ It is important to note that not all patients will download data and share it with their various health care providers. Often, as the recent study by Turvey et al. illustrates, laboratories get ordered before appointments, and patients bringing their data to appointments will not decrease duplicate testing. ${ }^{21}$ However, until efficient systems are 


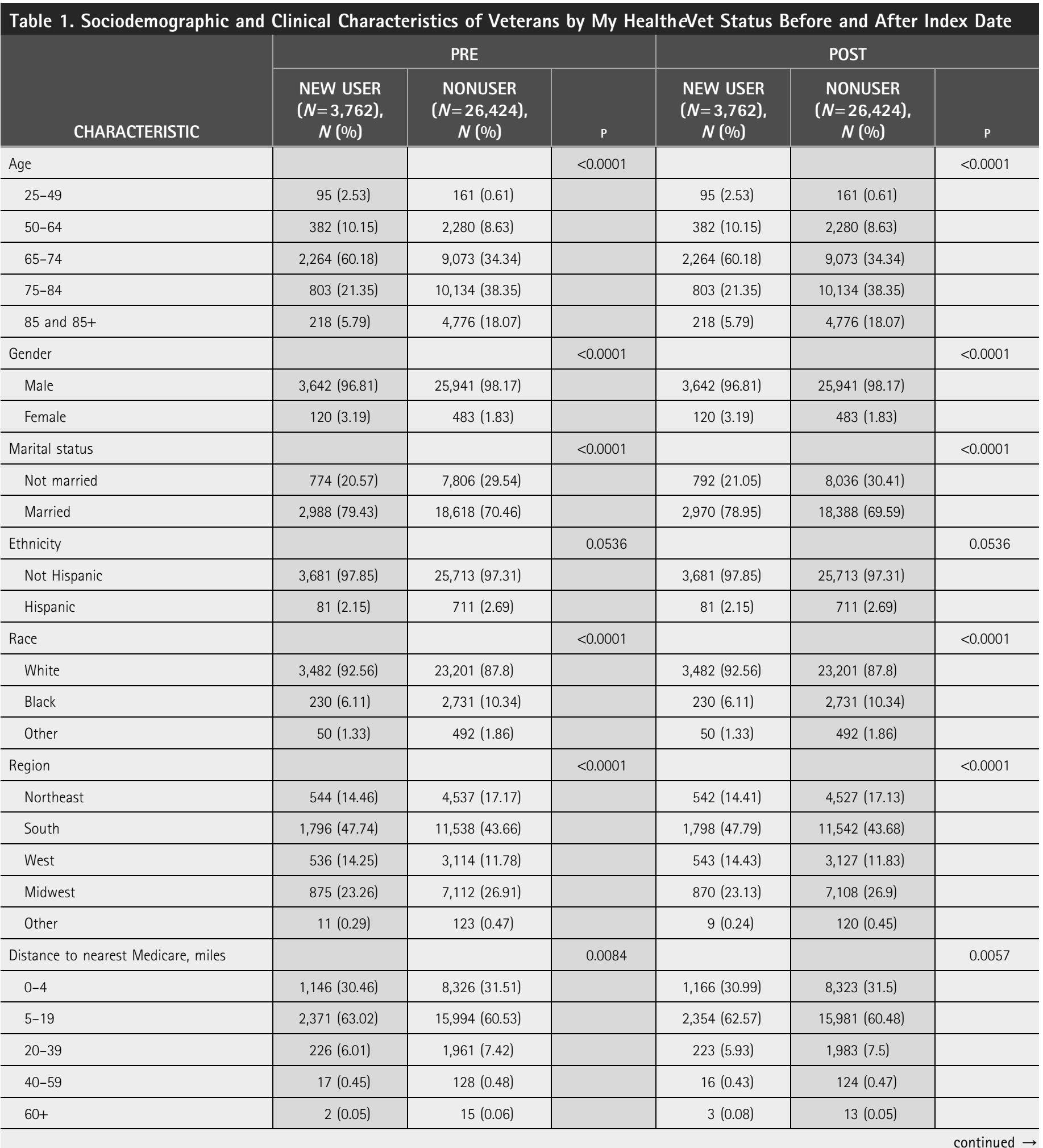




\begin{tabular}{|c|c|c|c|c|c|c|}
\hline \multirow[b]{2}{*}{ CHARACTERISTIC } & \multicolumn{3}{|c|}{ PRE } & \multicolumn{3}{|c|}{ POST } \\
\hline & $\begin{array}{c}\text { NEW USER } \\
(N=3,762) \\
N(\%)\end{array}$ & $\begin{array}{c}\text { NONUSER } \\
(N=26,424) \\
N(\%)\end{array}$ & $\mathbf{P}$ & $\begin{array}{c}\text { NEW USER } \\
(N=3,762) \\
N(\%)\end{array}$ & $\begin{array}{c}\text { NONUSER } \\
(N=26,424) \\
N(\%)\end{array}$ & $P$ \\
\hline Distance to nearest VA, miles & & & 0.0006 & & & 0.0001 \\
\hline $0-4$ & $935(24.85)$ & $5,947(22.51)$ & & $950(25.25)$ & $5,950(22.52)$ & \\
\hline $5-19$ & $1,115(29.64)$ & $7,492(28.35)$ & & $1,112(29.56)$ & $7,535(28.52)$ & \\
\hline $20-39$ & 759 (20.18) & $5,885(22.27)$ & & $757(20.12)$ & $5,845(22.12)$ & \\
\hline $40-59$ & 477 (12.68) & $3,627(13.73)$ & & $468(12.44)$ & $3,627(13.73)$ & \\
\hline $60+$ & $476(12.65)$ & $3,473(13.14)$ & & $475(12.63)$ & $3,467(13.12)$ & \\
\hline Rural & & & $<0.0001$ & & & $<0.0001$ \\
\hline Urban & $2,175(57.81)$ & $14,203(53.75)$ & & $2,236(59.44)$ & $14,433(54.62)$ & \\
\hline Rural & $1,587(42.19)$ & $12,221(46.25)$ & & $1,526(40.56)$ & 11,991 (45.38) & \\
\hline Enrollment group & & & $<0.0001$ & & & $<0.0001$ \\
\hline Group 1 & $1,695(45.06)$ & $7,116(26.93)$ & & $1,695(45.06)$ & $7,116(26.93)$ & \\
\hline Group 2 & $265(7.04)$ & $1,485(5.62)$ & & $265(7.04)$ & $1,485(5.62)$ & \\
\hline Group 3 & $424(11.27)$ & $2,563(9.7)$ & & $424(11.27)$ & $2,563(9.7)$ & \\
\hline Group 4 & $85(2.26)$ & $1,112(4.21)$ & & $85(2.26)$ & $1,112(4.21)$ & \\
\hline Group 5 & $421(11.19)$ & 4,878 (18.46) & & $421(11.19)$ & 4,878 (18.46) & \\
\hline Group 6 & 135 (3.59) & $428(1.62)$ & & 135 (3.59) & $428(1.62)$ & \\
\hline Group 7 & $70(1.86)$ & $800(3.03)$ & & $70(1.86)$ & $800(3.03)$ & \\
\hline Group 8 & 667 (17.73) & $8,042(30.43)$ & & $667(17.73)$ & $8,042(30.43)$ & \\
\hline Score community (HCC score) & & & $<0.0001$ & & & $<0.0001$ \\
\hline $0-0.49$ & $1193(31.71)$ & $4,043(15.3)$ & & $662(17.6)$ & $3,104(11.75)$ & \\
\hline $0.50-0.99$ & $1,367(36.34)$ & $12,636(47.82)$ & & $1,426(37.91)$ & $12,284(46.49)$ & \\
\hline $1.00+$ & $1,202(31.95)$ & $9,745(36.88)$ & & $1,674(44.5)$ & $11,036(41.77)$ & \\
\hline Median household income & & & $<0.0001$ & & & $<0.0001$ \\
\hline$<\$ 25 K$ & $11(0.29)$ & $141(0.53)$ & & $12(0.32)$ & $136(0.51)$ & \\
\hline$\$ 25 \mathrm{~K}$ to $\$ 49,999$ & $1,957(52.02)$ & $14,781(55.94)$ & & $1,952(51.89)$ & $14,797(56)$ & \\
\hline$\$ 50 \mathrm{~K}$ to $\$ 64,999$ & $1,214(32.27)$ & $8,104(30.67)$ & & $1,210(32.16)$ & $8,092(30.62)$ & \\
\hline$\$ 65 K+$ & $580(15.42)$ & 3,398 (12.86) & & $588(15.63)$ & 3,399 (12.86) & \\
\hline \% Families below poverty & & & 0.0191 & & & 0.0088 \\
\hline$<5$ & $22(0.58)$ & $76(0.29)$ & & $23(0.61)$ & $78(0.3)$ & \\
\hline $5-9$ & $504(13.4)$ & 3,332 (12.61) & & 507 (13.48) & $3,313(12.54)$ & \\
\hline $10-14$ & $1,124(29.88)$ & $8,144(30.82)$ & & $1,127(29.96)$ & $8,153(30.85)$ & \\
\hline $15-19$ & $1,447(38.46)$ & 10,109 (38.26) & & $1,447(38.46)$ & 10,115 (38.28) & \\
\hline $20+$ & 665 (17.68) & 4,763 (18.03) & & 658 (17.49) & 4,765 (18.03) & \\
\hline
\end{tabular}

HCC, Hierarchical Condition Category; VA, Veterans Affairs. 


\section{PATIENT PORTAL USE AND DUPLICATE LABORATORY TESTS}

$$
\begin{aligned}
& \hline \\
& \hline \\
& \hline
\end{aligned}
$$

Table 2. Hemoglobin A1c Regression Results

$95 \%$

CONFIDENCE

\begin{tabular}{l|c|c|c} 
& OR & P & $\begin{array}{c}\text { CONFIDENCE } \\
\text { INTERVAL }\end{array}$ \\
\hline MHV Blue Button user & 0.75 & 0.016 & $0.60-0.95$ \\
\hline Pre-post comparison & 0.85 & 0.013 & $0.75-0.97$ \\
\hline MHV Blue Button user ${ }^{2}$ pre-post & 0.36 & 0.000 & $0.24-0.54$ \\
\hline
\end{tabular}

Age

\begin{tabular}{c|c|c|c}
\hline $50-64$ & 1.28 & 0.558 & $0.56-2.97$ \\
\hline $65-74$ & 1.44 & 0.377 & $0.64-3.26$ \\
\hline $75-84$ & 1.17 & 0.709 & $0.51-2.72$ \\
\hline $85+$ & 0.80 & 0.620 & $0.33-1.92$ \\
\hline Gender & 0.57 & 0.074 & $0.31-1.06$ \\
\hline Married & 1.24 & 0.058 & $0.99-1.56$ \\
\hline Ethnicity (Hispanic) & 2.27 & 0.000 & $1.50-3.42$ \\
\hline Race (White) & 1.12 & 0.399 & $0.86-1.48$ \\
\hline Black & 0.91 & 0.793 & $0.44-1.88$ \\
\hline Other & \multicolumn{5}{|l}{} \\
\hline
\end{tabular}

Region (northeast)

\begin{tabular}{l|l|l|l}
\hline South & 1.01 & 0.920 & $0.78-1.31$ \\
\hline West & 0.78 & 0.160 & $0.55-1.10$ \\
\hline Midwest & 0.84 & 0.217 & $0.63-1.11$ \\
\hline Other & 1.10 & 0.867 & $0.36-3.41$ \\
\hline
\end{tabular}

Distance to nearest Medicare (0-4 miles), miles

\begin{tabular}{l|l|l|l}
\hline $5-19$ & 0.91 & 0.374 & $0.74-1.12$ \\
\hline $20-39$ & 0.80 & 0.314 & $0.52-1.24$ \\
\hline $40-59$ & 0.92 & 0.917 & $0.19-4.49$ \\
\hline $60+$ & 3.77 & 0.200 & $0.50-28.55$ \\
\hline
\end{tabular}

Distance to nearest VA (0-4 miles), miles

\begin{tabular}{l|l|l|l}
\hline $5-19$ & 0.94 & 0.615 & $0.74-1.19$ \\
\hline $20-39$ & 0.75 & 0.036 & $0.57-0.98$ \\
\hline $40-59$ & 0.97 & 0.856 & $0.71-1.34$ \\
\hline $60+$ & 1.11 & 0.496 & $0.82-1.51$ \\
\hline Rural & 1.07 & 0.548 & $0.86-1.31$ \\
\hline
\end{tabular}

Enrollment group (Group 1)

\begin{tabular}{l|l|l|l}
\hline Group 2 & 0.72 & 0.113 & $0.47-1.08$ \\
\hline Group 3 & 0.75 & 0.066 & $0.55-1.02$ \\
\hline Group 4 & 0.91 & 0.695 & $0.57-1.46$ \\
\hline Group 5 & 0.80 & 0.138 & $0.60-1.07$ \\
\hline
\end{tabular}

\begin{tabular}{l|c|c|c}
\multicolumn{1}{l|}{ Table 2. continued } & & & $\begin{array}{c}95 \% \\
\text { CONFIDENCE } \\
\text { INTERVAL }\end{array}$ \\
& OR & P & $0.23-0.82$ \\
\hline Group 6 & 0.43 & 0.011 & $0.24-1.01$ \\
\hline Group 7 & 0.49 & 0.053 & $0.66-1.06$ \\
\hline Group 8 & 0.84 & 0.146 & \\
\hline Score community (HCC score) & 1.26 & 0.061 & $0.99-1.61$ \\
\hline $0.50-0.99$ & 2.23 & 0.000 & $1.75-2.86$ \\
\hline $1.00+$ &
\end{tabular}

Median household income ( $\$ 0$ to $\$ 24,999$ )

\begin{tabular}{l|l|l|l}
\hline$\$ 25 \mathrm{~K}$ to $\$ 49,999$ & 0.62 & 0.389 & $0.21-1.84$ \\
\hline$\$ 50 \mathrm{~K}$ to $\$ 64,999$ & 0.79 & 0.680 & $0.26-2.43$ \\
\hline$\$ 65 \mathrm{~K}+$ & 0.76 & 0.649 & $0.24-2.44$ \\
\hline
\end{tabular}

$\%$ Families below poverty $(<5 \%)$

\begin{tabular}{l|l|l|l}
\hline $5-9$ & 1.94 & 0.219 & $0.67-5.60$ \\
\hline $10-14$ & 1.79 & 0.292 & $0.61-5.26$ \\
\hline $15-19$ & 2.03 & 0.210 & $0.67-6.11$ \\
\hline $20+$ & 2.41 & 0.124 & $0.78-7.41$ \\
\hline
\end{tabular}

${ }^{a}$ Controlled for VA facility.

MHV, My HealtheVet.

designed to allow providers in different organizations to access key data such as laboratory test or radiologic images, a tool like the VA Blue Button may be a means to complement provider-mediated HIE. A still larger policy question is whether patients should be responsible for sharing their data across systems of care.

Other factors were also associated with duplicate testing in our analysis. Veterans who lived between 20 and 39 miles to VA were less likely to have duplicate testing (Table 2). Reliance on VA care is associated with distance, that is, as distance to a VA facility, relative to the nearest Medicare hospital, increased, outpatient reliance on the VA decreased monotonically. ${ }^{47}$ However, the importance of distance to care is relative to the health status and resources of patients, complexity of service provided, and urgency of service needed. ${ }^{48}$ We found that sicker patients (HCC scores) were twice as likely to receive duplicate testing. Thus, Veterans who have better health status and live closer to a VA facility may choose to use care at that facility, potentially reducing duplicate testing. Veterans in Priority Group 6, which includes Vietnam and Persian Gulf War Veterans, among others, were also less 
likely to have duplicate testing. Although the reason for this finding is unknown, it is possible that these Veterans are relatively low users of the VA overall. Although we found a significant and important association using administrative data, we do not have any insights regarding reasons for differences in HbA1c testing frequency. Patients may, for example, be requesting additional tests be done by each provider. Some Medicare providers might not trust what is in Blue Button report, although this has not been found to be the case in previous studies. ${ }^{21,23}$ Non-VA providers may have limited knowledge of VA and its tests or even hold negative perceptions of the VA health care system, and so are inclined to reorder. Finally, as described above, providers may also order laboratory tests before visits, thus patientprovided information at the time of the visit cannot prevent duplication. ${ }^{21}$

\section{LIMITATIONS}

There are various limitations to this analysis. First, the raw number of individuals with duplicate testing is very small overall. However, Blue Button use is growing. The results of this study are significant because of the potential to decrease overlap among users who are not currently using the Blue Button. While the Veterans in the MHV group used Blue Button and downloaded laboratory data, it is not clear whether they shared laboratory data with their non-VA provider. If they downloaded the report, there is no way to know whether they were specifically reviewing their laboratory data. We also do not know the reasons a provider ordered the $\mathrm{HbA1c}$; in some cases, the repeat test may have been clinically indicated. Duplication of HbA1c decreased over time in both groups, and the reasons for this finding are not known. The need for authentication on the portal might have introduced bias in unknown ways. This analysis focused on one laboratory test, and thus we cannot comment on whether we would find the same differences in other tests or procedures. We were not able to address non-VA duplication of testing in younger Veterans. Zip code was used to determine urbanicity, but a person may have moved during study period. Furthermore, county-level data about income are only surrogate. We used HCC to make a single estimation of overall health status for each patient, however an individual's overall health status changes over time, and HCC is a proxy measure of health. We coded portal use as a dichotomous variable; however more use, or more recent use, may be a better predictor of information availability to the provider. Finally, Veterans using Blue Button may be different from those not using it in ways that could not be examined in this study, for example, patient engagement in their care. ${ }^{40}$

\section{Conclusion}

Patient portal features such as Blue Button and other consumer-oriented technologies can facilitate patient sharing of health information with providers across health care systems. ${ }^{49}$ Existing structures and processes create barriers for non-VA providers to access complete information about their patients who also use VA health care services. To fully realize an effective model of consumer-mediated HIE to improve care coordination, we must address the needs of different stakeholder groups. Patients may need more education and training about how best to leverage portal features to support HIE. Providers may need to be similarly educated and convinced of the value of the information that patients can access and share with them. Provider endorsement of consumer-mediated HIE could help further this model of sharing information.

Future work might examine the potential of portal features to reduce duplicate testing in other disease contexts. Future work must also focus on understanding what information is being shared between a patient and provider, when and why, necessitating the complementary use of mixed data collection and analysis approaches.

\section{Acknowledgments}

The views expressed in this article are those of the authors and do not necessarily represent the views of the Department of Veterans Affairs or the U.S. government.

\section{Disclosure Statement}

No competing financial interests exist.

\section{Funding Information}

This study was supported by the Department of Veterans Affairs, Office of Research and Development, Health Services Research and Development Service (IIR 14-041, Impact of My HealtheVet on Healthcare Use and Costs).

\section{REFERENCES}

1. Zhi M, Ding EL, Theisen-Toupal J, Whelan J, Arnaout R. The landscape of inappropriate laboratory testing: A 15-year meta-analysis. PLoS One 2013;8: e78962.

2. Eftekhari $S$, Yaraghi $N$, Singh R, Gopal RD, Ramesh R. Do health information exchanges deter repetition of medical services? ACM Trans Manage Inf Syst 2017;8:26.

3. Stewart BA, Fernandes S, Rodriguez-Huertas E, Landzberg M. A preliminary look at duplicate testing associated with lack of electronic health record interoperability for transferred patients. J Am Med Informatics Assoc 2010;17: 341-344.

4. Maciejewski ML, Wang V, Burgess JF, Bryson CL, Perkins M, Liu CF. The continuity and quality of primary care. Med Care Res Rev 2013;70:497-513. 


\section{PATIENT PORTAL USE AND DUPLICATE LABORATORY TESTS}

5. Levin A, Chaudhry MR, Djurdjev O, Beaulieu M, Komenda P. Diabetes, kidney disease and cardiovascular disease patients. Assessing care of complex patients using outpatient testing and visits: Additional metrics by which to evaluate health care system functioning. Nephrol Dial Transplant 2009;24: 2714-2720.

6. Sadoughi $F$, Nasiri $S$, Ahmadi $H$. The impact of health information exchange on healthcare quality and cost-effectiveness: A systematic literature review. Comput Methods Programs Biomed 2018;161:209-232.

7. French DD, Dixon BE, Perkins SM, Myers $\sqcup$, Weiner M, Zillich AJ, et al. Shortterm medical costs of a VHA health information exchange: A CHEERScompliant article. Medicine 2016;95:e2481.

8. Kerwin TC, Leighton $H$, Buch $K_{1}$ Avezbadalov A, Kianfar $H$. The effect of adoption of an electronic health record on duplicate testing. Cardiol Res Pract 2016;2016:1950191

9. Charlton ME, Mengeling MA, Schlichting JA, Jiang L, Turvey C, Trivedi AN, et al. Veteran Use of health care systems in rural states: Comparing VA and non-VA health care use among privately insured Veterans under age 65. J Rural Health 2016;32:407-417.

10. Humensky J, Carretta H, de Groot K, Brown MM, Tarlov E, Hynes DM. Service utilization of veterans dually eligible for VA and Medicare fee-forservice: 1999-2004. Medicare Medicaid Res Rev 2012;2:pii: mmr.002.03.a06.

11. Nguyen KA, Haggstrom DA, Ofner S, Perkins SM, French DD, Myers $\sqcup$, et al. Medication use among veterans across health care systems. Appl Clin Informatics 2017;8:235-249.

12. Ono SS, Dziak KM, Wittrock SM, Buzza CD, Stewart KR, Charlton ME, et al. Treating dual-use patients across two health care systems: A qualitative study. Fed Pract 2015;32:32-37.

13. Office of the National Coordinator for Health Information Exchange Technology. What are the different types of health information exchange? Available at https://www.healthit.gov/faq/what-are-different-types-healthinformation-exchange (last accessed January 30, 2020).

14. Hogan T, Nazi K, Luger T, Amante D, Smith B, Barker A, et al. Technologyassisted patient access to clinical information: An evaluation framework for blue button. JMIR Res Protoc 2014;3:e18.

15. Office of the National Coordinator for Health Information Exchange Technology. 2019. Available at https://www.healthit.gov/topic/health-itinitiatives/blue-button/join-the-blue-button-movement (last accessed January 30, 2020).

16. Office of the National Coordinator for Health Information Exchange Technology. Blue Button fact sheet. 2014. Available at https://www.healthit .gov/sites/default/files/factsheets/blue-button-fact-sheet-2014-feb_0.pdf (last accessed January 30, 2020).

17. Jones JB, Weiner JP, Shah NR, Stewart WF. The wired patient: Patterns of electronic patient portal use among patients with cardiac disease or diabetes. $J$ Med Internet Res 2015;17:e42.

18. Sue VM, Griffin MT, Allen JY. Beyond adoption: Individual differences in the use of personal health record features in an integrated healthcare organization. Int $J$ Biomed Eng Technol 2013;11:252-269.

19. D'Amore JD, Sittig DF, Ness RB. How the Continuity of Care Document can advance medical research and public health. Am J Public Health 2012;102: E1-E4.

20. D'Amore JD, Sittig DF, Wright A, lyengar MS, Ness RB. The promise of the CCD: Challenges and opportunity for quality improvement and population health. AMIA Annu Symp Proc 2011;2011:285-294.

21. Turvey $C L$, Klein DM, Witry M, Klutts JS, Hill EL, Alexander B, et al. A pilot randomized controlled trial of the department of veterans affairs blue button. Appl Clin Informatics 2016;7:765-776.

22. My HealtheVet Product Home. 2019. Available at https://www.myhealth va.gov/mhv-portal-web/web/myhealthevet/home
23. Klein DM, Pham K, Samy L, Bluth A, Nazi KM, Witry M, et al. The Veteraninitiated electronic care coordination: A multisite initiative to promote and evaluate consumer-mediated health information exchange. Telemed $J$ E Health 2017;23:264-272.

24. Lau M, Campbell H, Tang T, Thompson DJS, Elliott T. Impact of patient use of an online patient portal on diabetes outcomes. Can J Diabetes 2014;38: 17-21.

25. Toscos T, Daley C, Heral L, Doshi R, Chen YC, Eckert GJ, et al. Impact of electronic personal health record use on engagement and intermediate health outcomes among cardiac patients: A quasi-experimental study. J Am Med Informatics Assoc 2016;23:119-128.

26. Shimada SL, Allison JJ, Rosen AK, Feng H, Houston T. Sustained use of patient portal features and improvements in diabetes physiological measures. J Med Internet Res 2016;18:e179.

27. Smith BM. HSR\&D 14-041 impact of MyHealtheVet on healthcare use and costs. Department of Veterans Affairs Health Services Research and Development Service.

28. Pivovarov R, Albers DJ, Hripcsak G, Sepulveda JL, Elhadad N. Temporal trends of hemoglobin A1c testing. J Am Med Informatics Assoc 2014;21:1038-1044.

29. American Diabetes Association. Standards of medical care in diabetes-2012. Diabetes Care 2012;35(Suppl 1):S11-S63.

30. American Diabetes Association. Standards of medical care in diabetes-2013. Diabetes Care 2013;36(Suppl 1):S11-S66.

31. American Diabetes Association. Standards of medical care in diabetes-2014. Diabetes Care 2014;37(Suppl 1):S14-S80.

32. Veterans Affairs Information Resource Center WAIR. VIReC Research User Guide: Fiscal Year 2009 VHA Medical SAS Inpatient Datasets. 2011.

33. Thomas AJ, Eberly LE, Smith GD, Neaton JD. ZIP-code-based versus tract-based income measures as long-term risk-adjusted mortality predictors. Am J Epidemiol 2006;164:586-590

34. Abrams TE, Vaughan-Sarrazin M, Kaboli PJ. Mortality and revascularization following admission for acute myocardial infarction: Implication for rural Veterans. J Rural Health 2010;26:310-317.

35. Pope GC, Kautter J, Ellis RP, Ash AS, Ayanian JZ, lezzoni LI, et al. Risk adjustment of medicare capitation payments using the CMS-HCC model. Health Care Financ Rev 2004;25:119-141.

36. Morgan RO, Petersen LA, Hasche JC, Davila JA, Byrne MM, Osemene NI, et al. VHA pharmacy use in veterans with Medicare drug coverage. Am J Manag Care 2009;15:e1-e8.

37. Zeng F, An JJ, Scully R, Barrington $C$, Patel BV, Nichol MB. The impact of valuebased benefit design on adherence to diabetes medications: A propensity score-weighted difference in difference evaluation. Value Health 2010;13: 846-852.

38. Austin PC. A critical appraisal of propensity-score matching in the medical literature between 1996 and 2003. Stat Med 2008;27:2037-2049.

39. Karaca-Mandic $P$, Norton EC, Dowd B. Interaction terms in nonlinear models. Health Serv Res 2012;47(Pt 1):255-274.

40. Turvey CL, Klein D, Fix G, Hogan TP, Woods S, Simon SR, et al. Blue button use by patients to access and share health record information using the department of veterans affairs' online patient portal. J Am Med Informatics Assoc 2014;21:657-663.

41. Ayabakan S, Bardhan IR, Zheng Z, Kirksey K, editors. Value of health information sharing in reducing healthcare waste: An analysis of duplicate testing across hospitals. Thirty-Fifth International Conference on Information Systems. Auckland: Association for Information Systems, 2014.

42. Eftekhari S, Yaraghi N, Singh R, Gopal R, Ramesh R. Do Health Information Exchanges Deter Repetition of Medical Services? University of Connecticut School of Business Research Paper No 17-032017. 


\section{WAKEFIELD ET AL.}

43. Everson J, Kocher KE, Adler-Milstein J. Health information exchange associated with improved emergency department care through faster accessing of patient information from outside organizations. J Am Med Inform Assoc 2017;24: e103-e10.

44. Jung HY, Vest JR, Unruh MA, Kern LM, Kaushal $R$, Investigators $H$. Use of health information exchange and repeat imaging costs. J Am Coll Radiol 2015;12(Pt B):1364-1370

45. Gellad WF, Zhao X, Thorpe CT, Mor MK, Good CB, Fine MJ. Dual use of department of veterans affairs and medicare benefits and use of test strips in veterans with type 2 diabetes mellitus. JAMA Intern Med 2015;175: 26-34.

46. Slovis BH, Lowry $T$, Delman BN, Beitia AO, Kuperman G, DiMaggio $C$, et al. Patient crossover and potentially avoidable repeat computed tomography exams across a health information exchange. J Am Med Informatics Assoc 2017;24:30-38.

47. Petersen LA, Byrne MM, Daw CN, Hasche J, Reis B, Pietz K. Relationship between clinical conditions and use of veterans affairs health care among Medicare-enrolled veterans. Health Serv Res 2010;45:762-791.

48. Buzza C, Ono SS, Turvey C, Wittrock S, Noble M, Reddy G, et al. Distance is relative: Unpacking a principal barrier in rural healthcare. J Gen Intern Med $2011 ; 26($ Suppl 2):648-654.
49. Klein DM, Fix GM, Hogan TP, Simon SR, Nazi KM, Turvey CL. Use of the blue button online tool for sharing health information: Qualitative interviews with patients and providers. J Med Internet Res 2015;17:e199.

Address correspondence to:

Bonnie J. Wakefield, PhD

Sinclair School of Nursing

University of Missouri

S313 SSON

Columbia, MO 65203

USA

E-mail: wakefieldb@missouri.edu

Received: September 8, 2019

Revised: November 20, 2019

Accepted: November 22, 2019

Online Publication Date: February 11, 2020 